\title{
Valve-Induced Water Hammer and Column Separation in a Pipeline Apparatus
}

\author{
Uroš Karadžić1 1, - Vladimir Bulatović1 - Anton Bergant² \\ ${ }_{1}$ University of Montenegro, Faculty of Mechanical Engineering, Montenegro \\ 2 Litostroj Power, Slovenia
}

\begin{abstract}
A flexible experimental apparatus for investigating water hammer and column separation in an unsteady friction-dominated pipelines has been developed and designed. The apparatus has been tested for steady and unsteady flow conditions. Transient cavitation and column separation phenomena have been observed in a number of experimental runs. Water hammer has been triggered by both the closing and opening of electro-pneumatic (EV) and hand-operated (HV) valves. The experimental data have been compared with results given from in-house numerical code written in Visual Fortran based on the method of the characteristics (MOC) with a convolution-based unsteady friction model (CBM) included. The column separation and transient cavitation phenomena are modelled via a discrete gas cavity model (DGCM). There is good agreement between the experimental and numerical results; the model is robust and, therefore, it is recommended for engineering practice. In addition, the influence of variations of the pressure wave speed and the uncertainty in flow rate measured by the electromagnetic flow meter are also investigated.
\end{abstract}

Keywords: water hammer, experimental setup, column separation, unsteady friction, piping systems

\section{INTRODUCTION}

The phrase "water hammer" describes the generation, propagation and reflection of pressure waves along pipelines of pressurized liquid systems that are associated with changes in flow conditions. Uncontrolled water hammer can disturb the operation of hydraulic systems and, in the worst case, damage and destroy system components. Rises or drops in water hammer pressure may be controlled by installing protecting devices, the appropriate control of operating regimes or the redesigning of an originally developed pipeline layout [1] and [2]. The classic form of water hammer may be affected by transient cavitation and column separation, unsteady friction effects, visco-elastic behaviour of the pipe wall and fluid-structure interaction (FSI) [3] and [4]. Transient vaporous cavitating pipe flow occurs when the pressure drops to the liquid vapour pressure. The fluid also contains a small amount of free and released gas. The gas and vapour bubbles form pockets (cavities) [1] and [5], which can break the fluid column at the system boundaries or at the high points, i.e. a phenomenon known as "column separation" [6] and [7]. The collapse of a vapour cavity may induce short-duration pressure pulses with values higher than the pressure initially given by the Joukowsky equation [8]. The value of the friction factor during the water hammer event is different than its value during the steady flow. The friction factor can be expressed as a sum of two parts: quasi-steady $\left(f_{q}\right)$ and unsteady $\left(f_{u}\right)$ [9]. The unsteady part attempts to represent transientinduced changes in the velocity profile [10] to [12], and it is important for fast transients [13] and [14]. For pipelines that are not completely fixed, FSI effects have to be taken into consideration [15] to [17]. The viscoelastic behaviour of the pipe wall is significant in cases in which the pipe is made from plastic materials, such as polyethylene PE, high-density polyethylene HDPE, polyvinyl chloride PVC and acrylonitrile butadiene styrene ABS [18] to [21]. The experimental test rig has been developed primarily for an investigation of the transient cavitation, column separation and unsteady friction during the water hammer events.

In the first part of the paper, mathematical tools for modelling water hammer, unsteady friction and transient vaporous cavitation (liquid column separation) are presented. Water hammer is fully described by two hyperbolic partial differential equations: the continuity and the momentum equation that are traditionally numerically solved by the method of the characteristics [1] and [2]. The improved convolution-based unsteady friction model [22] is explicitly incorporated into the staggered grid of the method of characteristics. The developed numerical code is further improved by including a discrete gas cavity model for modelling transient cavitation and column separation [1] and [23]. The Ghidaoui et al. coefficient $P$ is calculated, and it is proved that developed experimental setup is unsteady friction dominated [24]. The paper continues with detailed description of the experimental apparatus for measurement of water hammer pressure waves. In the second part of the paper, the influence of variations of pressure wave speed [25] and uncertainty in flow rate measured by the electromagnetic flow meter are 
investigated. The paper concludes with a number of comparisons between the experimental and the numerical results given from the fast closing and opening of the downstream end valve. The numerical scheme that includes discrete gas cavities and unsteady friction effects yields accurate and robust results.

\section{WATER HAMMER WITH COLUMN SEPARATION}

Water hammer is manifested by a pressure rise or drop along the liquid-filled pipeline due to a change of flow conditions. The simplified form of the equation of continuity and the momentum equation is [1] and [2]:

$$
\begin{gathered}
\frac{\partial H}{\partial t}+\frac{a^{2}}{g A} \frac{\partial Q}{\partial x}=0, \\
\frac{\partial H}{\partial x}+\frac{1}{g A} \frac{\partial Q}{\partial t}+\frac{f Q|Q|}{2 g D A^{2}}=0 .
\end{gathered}
$$

The unknown variables in Eqs. (1) and (2) are the piezometric head $H$ and the discharge $Q$. The method of the characteristics (MOC) transformation of Eqs. (1) and (2) gives the following set of the compatibility equations that are solved algebraically [1] and [2]:

$$
\frac{d H}{d t} \pm \frac{a}{g A} \frac{d Q}{d t} \pm \frac{a f Q|Q|}{2 g D A^{2}}=0,
$$

that are valid along the characteristic lines $d x / d t= \pm a$.

At a boundary (reservoir, valve), a device-specific equation replaces one of the MOC water hammer compatibility equations.

The cavitating pipe flow usually occurs as a result of very low pressures during water hammer events. Cavitation may occur as localized cavitation with a large void fraction (column separation) or as distributed cavitation with a small void fraction. To date, numerous numerical models have been developed for simulating transient vaporous cavitation, one of which is a discrete gas cavity model (DGCM) that performs accurately over a broad range of input parameters [8]. The DGCM allows gas cavities to form at computational sections within the MOC numerical grid. A liquid phase with a constant wave speed is assumed to occupy the computational reach. The DGCM is fully described by the two water hammer compatibility equations and two additional equations; the continuity equation for the gas volume and the ideal gas equation with assumption of isothermal behaviour of the free gas, respectively, [1] and [23],

$$
\frac{d V_{g}}{d t}=Q_{\text {out }}-Q_{\text {in }},
$$

$$
V_{g}=\alpha_{0} V\left(\frac{p_{0}^{*}}{p_{g}^{*}}\right) .
$$

The numerical solution of Eqs. (3) to (5) can be found elsewhere [1] and [26].

The investigations of Ghidaoui et al. [24] indicate that accurate, physically based, unsteady friction models are required if the ratio of radial diffusion time scale to the pressure wave time scale is in order of one or less. The ratio is defined as [24]:

$$
P=\frac{2 D /(\sqrt{f} Q / A)}{L / a} .
$$

When the parameter $P$ is close to one, then the vorticity generated at the pipe wall by the water hammer pressure wave diffuses through the complete pipe core and alters the pre-existing turbulent state [27]. This is the situation in the cases investigated in this paper; it implies that the developed experimental apparatus is an unsteady friction dominated one, i.e. the unsteady friction model is needed for proper estimation of skin friction losses during rapid transient events. For this purpose, an improved convolution based unsteady friction model is used [22]. Typical industrial examples of this situation are oil-hydraulic systems [28]. Such systems are part of a number of control systems in power industry, and their accurate modelling is essential for control simulations [29]. The convolutionbased model (CBM) has been analytically developed by Zielke for transient laminar flow [30]. This model produces correct results for a number of flow types using analytical expressions [31]. Column separation is a relatively short duration event with a wide range of flow event types [8]. Simple instantaneous acceleration-based models need to be calibrated (empirical coefficients) [12] and fail for certain types of flow [31]. In the improved Vítkovský et al. CBM model [22] the unsteady friction factor is expressed as a finite sum of $N_{k}$ functions $y_{k}(t)$,

$$
f_{u}=\frac{32 v A}{D Q|Q|} \sum_{k=1}^{N_{k}} y_{k}(t)
$$

with,

$$
y_{k}(t)=\int_{0}^{t} \frac{\partial Q}{\partial t^{*}} m_{k} \exp \left[-n_{k} K\left(t-t^{*}\right)\right] d t^{*},
$$

where the constant $K=4 v / D^{2}$ converts the time $t$ into the dimensionless time $\tau=4 v t / D^{2}$. The maximum 
number of exponential terms is $N_{k, \max }=10$. The coefficients of the exponential sum $m_{k}$ and $n_{k}$ have been developed for Zielke's [30] and Vardy-Brown's weighting functions [32] and [33] for laminar and turbulent transient flow, respectively.

\section{EXPERIMENTAL APPARATUS}

A flexible experimental apparatus for investigating water hammer and column separation in unsteady friction dominated pipeline has been designed and constructed [34]. The apparatus shown in Fig. 1 is composed of a high pressure upstream end reservoir (HPR) (design pressure: 22 bar), a $54.23 \mathrm{~m}$ long steel pipeline (design pressure: 250 bar) with an inner diameter of 18 and $2 \mathrm{~mm}$ wall thickness, a fast closing electro-pneumatic ball valve (EV) (maximum working pressure: 63 bar; operating pressure: from 2 to 4 bar; closing and opening time: from 10 to 20 $\mathrm{ms}$ ) that induces a transient event and a low pressure downstream end reservoir (LPR). The EV is operated by a solenoid valve (Burkert 5/2) and pneumatic actuator (Prisma). In addition, water hammer can be induced by a hand-operated valve (HV1) (maximum working pressure: 63 bar), which enables closures with different closing time. Both valves (EV and HV1) are equipped with a displacement sensor (VAS) (Positek P500.90BL, measurement range: 0 to $90^{\circ}$, frequency response: $>10 \mathrm{kHz}$ ) which measures the change of the valve angle during its closing or opening. Four dynamic pressure transducers (DPT) (Dytran $2300 \mathrm{~V} 4$, pressure range: from 0 to $69 \mathrm{bar}$, sensitivity: $5 \mathrm{mV} / 0.069$ bar, uncertainty [35]: $\pm 0.1 \%$ ) have been installed equidistantly along the pipeline for capturing high frequency pressure changes. At the upstream and the downstream end of each DPT, a hand-operated valve is installed. Dynamic pressure transducers are marked as D1 (next to the EV), D2 (18.4 m upstream from the EV), D3 (36.1 m upstream from the EV), and D4 (next to the HPR; see Fig. 1). For the evaluation of the initial conditions in the system, two pressure transducers (SPT) (Endress+Hauser PMP131, pressure range: from 0 to 10 bar, uncertainty: $\pm 0.5 \%)$ are installed, one at the HPR and one at the downstream end of the pipeline just in front of the needle valve (NV) (Swagelok, maximum pressure: 344 bar). The needle valve is used for adjustment of the initial pipe flow rate (discharge). The initial discharge and consequently the initial average flow velocity is measured by the electromagnetic flow meter (EF) (Krohne OPTIFLUX 4000F IFC 300C, uncertainty: $\pm 0.2 \%)$ and by the redundant ultrasonic one (UF) (Krohne UFM 610P, uncertainty: $\pm 2 \%$ ).
Pressure in the HPR is kept constant during the transient event by compressed air that is supplied from the compressor (CP) and the air reservoir (AR). The high precision air pressure regulator (HPPR) (SMC $\mathrm{AF} 40-\mathrm{F} 04 \mathrm{D}$, pressure range: from 0 to $1 \mathrm{MPa}$ ) is used for control of the initial pressure in the system as well as for control of the EV closing and opening pressure. All measured data are collected by the data acquisition system (DAS) (Measurement Computing USB$1608 \mathrm{FS}$, sample rate: up to $100 \mathrm{kHz}$ ) that is connected to PC. HPR is supplied with water from the tap water supply system. The lime-scale neutralizer (LN) and the check valve $(\mathrm{CV})$ are installed in the water supply line. The water temperature is continuously monitored by the thermometer (TM) installed in LPR.

Five sets of measurements have been performed. For all sets the initial pressure in HPR was adjusted to 4 bar. In the first set of measurements, the water hammer event has been initiated by the fast closing or opening of the downstream end valve using either the electro-pneumatic valve or hand-operated valve at different pipe velocities (from 0.26 to $2.34 \mathrm{~m} / \mathrm{s} ; 192$ measurements). In the second set of measurements, the water hammer event has been initiated only with the hand-operated valve. Closing and opening of the valve has been done with different closing/opening times at different flow velocities (from 1.20 to 2.12 $\mathrm{m} / \mathrm{s} ; 18$ measurements). The water hammer event in the third set of measurements has been triggered by closing the hand-operated valves along the pipeline. Measurements have been carried out for four positions of the hand valves (valves HV1 to HV4; see Fig. 1; 106 measurements). In the fourth set of measurements, the HV4d at the HPR and the HV1 at the downstream end of the pipeline have been closed at the same time ( 26 measurements). In the fifth set of the measurements three types of experiments have been performed: (1) rapid opening of the hand-operated valve HV4d at the HPR (other HVs are open) for different openings of the needle valve (filling of the pipeline); (2) filling the last third of the pipeline - rapid opening of HV2d and closed valve HV1 at the downstream end of the pipeline: (3) emptying the pipeline; rapid opening of the HV1 at the downstream end of pipeline with HV4u at the HPR closed (24 measurements).

\section{COMPARISON OF EXPERIMENTAL AND NUMERICAL RESULTS}

The experimental apparatus has been tested for a number of steady and unsteady flow conditions. The experiments have been performed for the different initial flow velocities (from 0.26 to $2.34 \mathrm{~m} / \mathrm{s}$ ) at the 


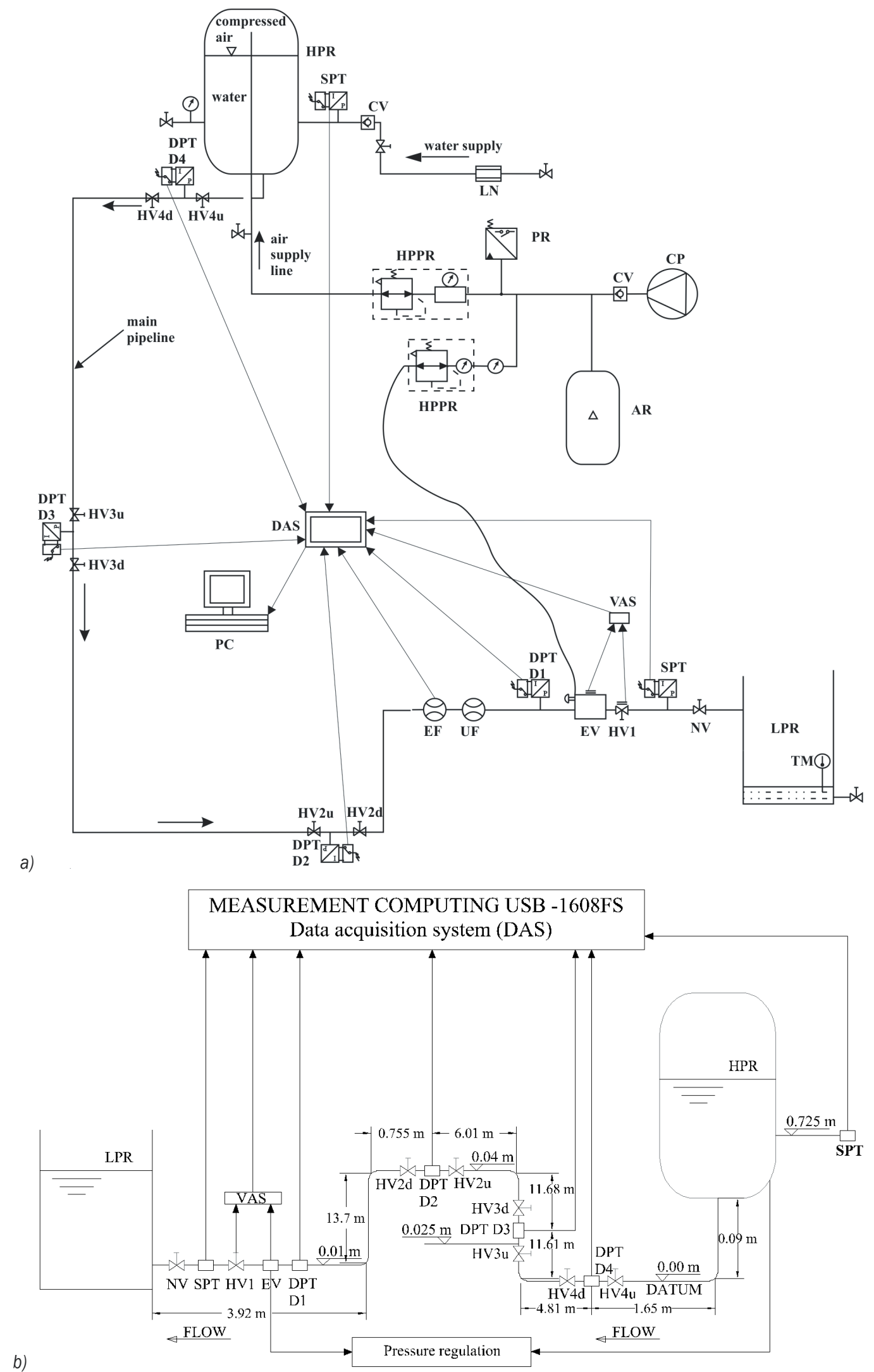

Fig. 1. Water hammer and column separation pipeline apparatus; a) schematic layout of the apparatus; b) longitudinal profile of the pipeline 
constant initial pressure in the HPR $\left(p_{r}=4\right.$ bar). All experiments have been carried out as follows: the initial pressure in the HPR was adjusted and maintained at a constant level during the transient tests, using a high precision air pressure regulator (HPPR). After that, the initial velocity in the pipeline was adjusted by an appropriate opening of the needle valve. The water hammer event was triggered by fast closing or opening of the downstream end valve, using either the EV or the HV1. In addition, slow closing and opening of the HV1 were also investigated.

In this paper, the convergence and stability of the used numerical model were checked first. Then, the influence of variations of the pressure wave speed were investigated. This is done because the wave speed is usually not known with accuracy better than $5 \%$ [25]. Furthermore, the uncertainty of the flow rate measured by the electromagnetic flow meter was investigated because it is well known that this device could not measure the flow rate (average pipe flow velocity) very accurately. The measured value of the initial pipe flow velocity varied $\pm 2 \%$. Then, the examples of fast closing and opening of the EV at the downstream end of the pipeline were examined. This paper ends with the examination of the impact of the pipeline length on the water hammer head rise by the fast closing of hand-operated valves along the pipeline. All investigated cases with their description are summarized in the Table 1.

Table 1. Summary of investigated cases

\begin{tabular}{llc}
\hline & Description & $\begin{array}{c}\text { Initial/final pipe } \\
\text { velocity }[\mathrm{m} / \mathrm{s}]\end{array}$ \\
\hline Test A & Fast closing of EV & 2.07 \\
\hline Test B & Fast closing of EV & 2.01 \\
\hline Test C & Fast closing of EV & 2.05 \\
\hline Test D & Fast opening of EV & 2.01 \\
\hline Test E & Fast closing of HVs along pipeline & 2.00 \\
\hline
\end{tabular}

\subsection{Convergence and Stability of Numerical Model}

The numerical solution of the developed numerical code should satisfy the convergence and stability criteria. Convergence relates to the behaviour of the
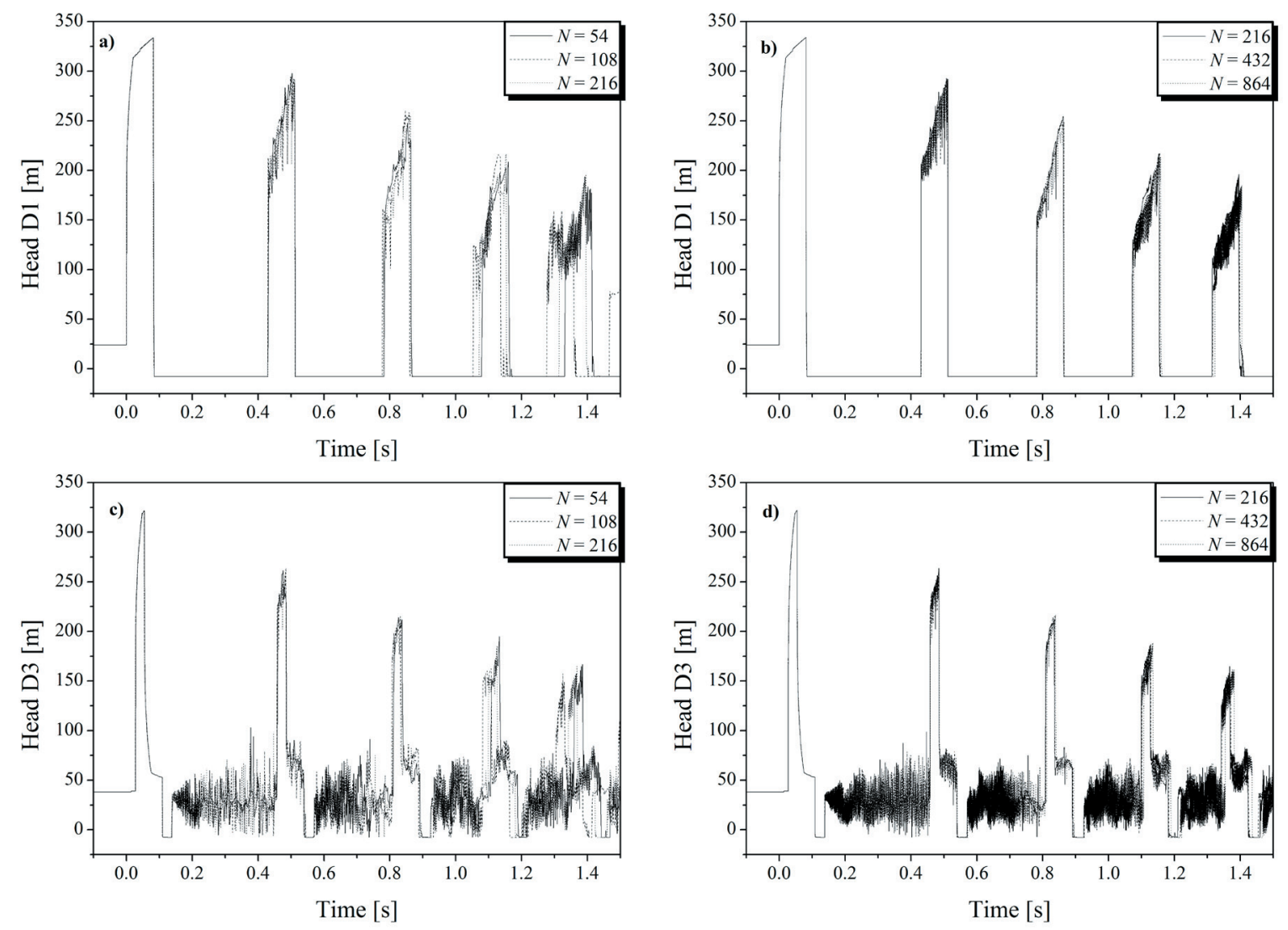

Fig. 2. Numerical analysis for Test $A$ : $p_{r}=4$ bar, $v_{0}=2.07 \mathrm{~m} / \mathrm{s}, a=1349 \mathrm{~m} / \mathrm{s}, P=2.74$; a) $N=\{54,108,216\}$ at $D 1$, b) $N=\{216,432,864\}$ at $D 1, c) N=\{54,108,216\}$ at $D 3, d) N=\{216,432,864\}$ at $D 3$ 
solution as $\Delta x$ and $\Delta t$ tends to zero while the stability is concerned with round-off error growth [2]. The influence of different numbers of computational reaches $N=\{54,108,216,432,864\}$ is investigated. Fig. 2 shows the numerical results for the fast closing of EV (Test A) with initial flow velocity $v_{0}=2.07 \mathrm{~m} / \mathrm{s}$ with severe cavitation. The water hammer wave speed used in simulations is $a=1349 \mathrm{~m} / \mathrm{s}$ and the weighting factor used in numerical solution of Eq. (4) [1] and [26] is $\psi=1$. The numerical results are consistent for higher number of reaches (Figs. 2b and d). For a smaller number of reaches, the numerical results are practically the same for the first three pressure pulses (Figs. 2a and c). After that, the discrepancies are obvious. Along the pipeline, a number of discrete vapour cavities occur as do distributed cavitation zones. The collapses of small cavities along the pipe produce high-frequency pressure peaks that are not repeatable in experiments nor in computations [26]. Some pressure spikes along the pipe occurred in different times as number of computational reaches increase. However, high frequency pressure peaks along the pipe do not significantly affect the main pressure pulses. Generally, the magnitude and timing of the main pressure pulses predicted by the developed numerical model converge as the number of reaches is increased.

\subsection{Sensitivity Analysis to Input Parameters}

An important feature of the numerical analysis is the sensitivity of numerical model results to input parameters. The influence of variations the wave speed and the flow rate will be investigated.

The calculated pressure wave speed in the pipeline is:

$$
a=\sqrt{\frac{K / \rho}{1+c_{1}(K D / E e)}}=1402.7 \mathrm{~m} / \mathrm{s}
$$

in which, the dimensionless parameter that describes the effect of pipe constraint condition on the wave speed is $c_{1}=1.12$ [1], the water bulk modulus of elasticity $K=2.18 \mathrm{GPa}$, Young's modulus of elasticity of pipe material $E=200 \mathrm{GPa}$, and the water density $\rho=998.2 \mathrm{~kg} / \mathrm{m}^{3}$. The measured value of the pressure wave speed is obtained from the measured time for a water hammer wave to travel between the closed valve (position of dynamic pressure transducer D1) and the position of the first nearest transducer D2; its value is $a=L / t=18.4 / 0.012957=1420 \mathrm{~m} / \mathrm{s}$ (uncertainty: $\pm 0.1 \%)$. The measured value of the pressure wave speed is then varied between $\pm 5 \%$, i.e. $a_{-5 \%}=1349$ $\mathrm{m} / \mathrm{s}$ and $a_{+5 \%}=1491 \mathrm{~m} / \mathrm{s}$. With these three wave speed values, numerical calculations are performed and compared with the results of measurements.
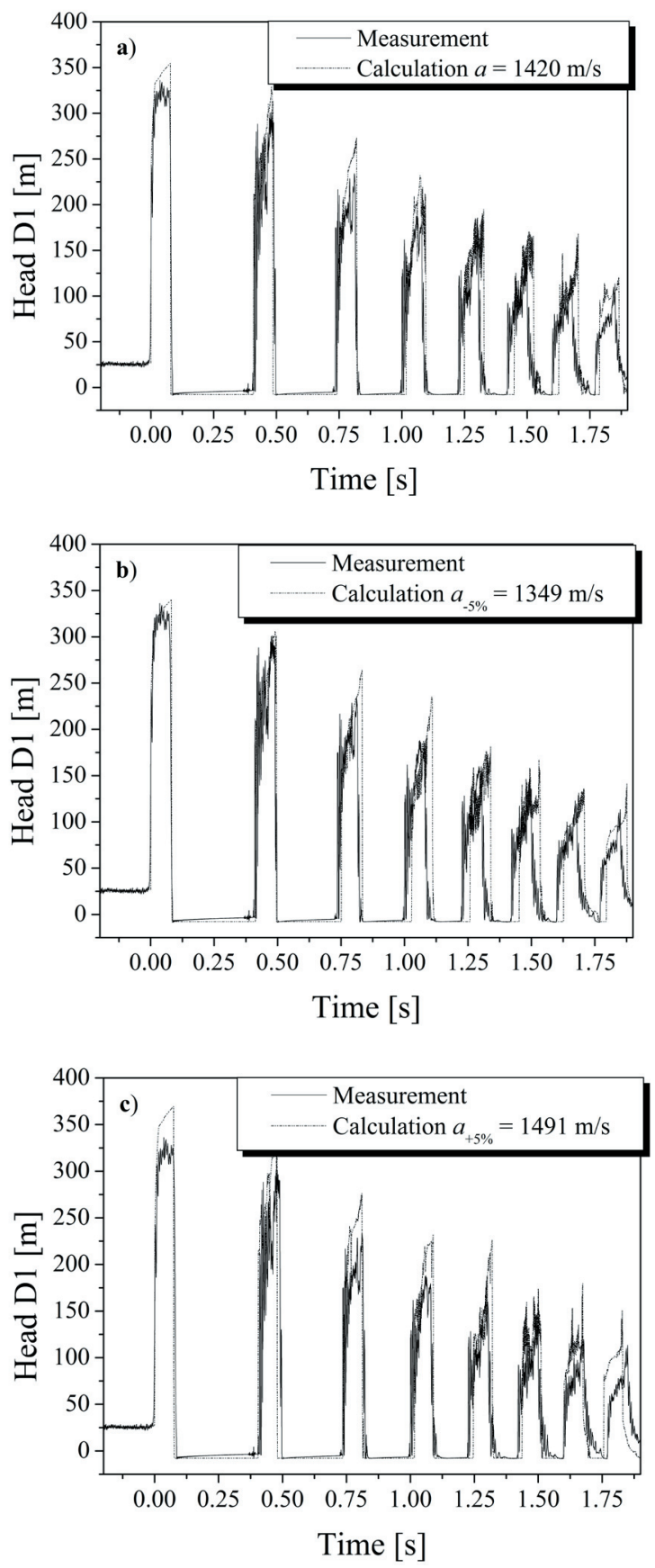

Fig. 3. Comparisons of heads at $D 1$ for Test $B$; a) $a=1420 \mathrm{~m} / \mathrm{s}$, b) $a_{-5 \%}=1349 \mathrm{~m} / \mathrm{s}$, and c) $a_{+5 \%}=1491 \mathrm{~m} / \mathrm{s}$ at $v_{0}=2.01 \mathrm{~m} / \mathrm{s}$

The experimental run with rapid EV closure has been selected for the analysis (initial pressure in HPR: $p_{r}=4$ bar; initial flow velocity in the system: $v_{0}=2.01 \mathrm{~m} / \mathrm{s}$; Test B). The initial flow for this run is turbulent with Reynolds number $\operatorname{Re}=36,100$. For 
the measured value of the wave speed $a=1420 \mathrm{~m} / \mathrm{s}$ and the initial pipe flow velocity $v_{0}=2.01 \mathrm{~m} / \mathrm{s}$, the Ghidaoui et al. parameter is $P=2.97$. An even number of pipeline reaches of $N=108$ has been selected and the corresponding numerical time step is $\Delta t=$ $3.59 \times 10^{-4}$ s. Fig. 3 shows comparisons of heads at the downstream end valve (position D1). The EV measured closing time is $t_{c}=0.016 \mathrm{~s}$, which is much shorter than the water hammer wave reflection time $2 L / a=0.0764 \mathrm{~s}$. The fast closing of the EV produces water hammer with liquid column separation [1] and [5]. The existence of a large vapour cavity at the valve is represented by a vapour pressure line. The maximum measured head at the EV (DPT D1) is $H_{\max D 1}=333.6 \mathrm{~m}$. The maximum calculated head occurs when the first reflected wave arrives back to the $\mathrm{EV}$ and its value is $H_{\max D 1}=\{338.6 ; 351.5 ; 368.1\}$ $\mathrm{m}$ for $a=\{1349,1420,1491\} \mathrm{m} / \mathrm{s}$, respectively.

The absolute difference between the measured and the calculated values is $\{5.0 ; 17.9 ; 34.5\} \mathrm{m}$ for $a=\{1349,1420,1491\} \mathrm{m} / \mathrm{s}$, respectively. The results with the wave speed $a_{-5 \%}=1349 \mathrm{~m} / \mathrm{s}$ yield the best fit with the results of measurement for the first pressure pulse; therefore, the lowest value of the wave speed is $a_{-5 \%}=1349 \mathrm{~m} / \mathrm{s}$ is used this paper.

The next step is to verify the influence of flow rate measured by the electromagnetic flow meter. The value of the initial pipeline flow velocity is varied $\pm 2 \%$ i.e. $v_{0-2 \%}=2.01-2 \%=1.97 \mathrm{~m} / \mathrm{s}$ and $v_{0+2 \%}=2.01+2 \%=2.05 \mathrm{~m} / \mathrm{s}$. The value of the pressure wave speed is $a_{-5 \%}=1349 \mathrm{~m} / \mathrm{s}$ and the numerical time step is $\Delta t=3.77 \times 10^{-4} \mathrm{~s}$. Fig. 4 presents comparisons of heads at the dynamic pressure positions D1 for different values of the initial velocity. The maximum calculated heads are $H_{\max D 1}=\{333.4 ; 338.6 ; 345.1\}$ $\mathrm{m}$ for $v_{0}=\{1.97 ; 2.01 ; 2.05\} \mathrm{m} / \mathrm{s}$, respectively. The absolute differences between the measured and the calculated values are $\{0.2 ; 5.0 ; 11.5\} \mathrm{m}$ for $v_{0}=\{1.97 ; 2.01 ; 2.05\} \mathrm{m} / \mathrm{s}$, respectively. The maximum value of the calculated head with initial flow velocity reduced by $2 \%$ compared to the measured value coincides the best (Fig. 4a). Furthermore, the numerical results with $v_{0-2 \%}$ have less phase difference than the results with $v_{0}$ and $v_{0+2} \%$ when they are compared with the results of measurements. Thus, the measured initial flow velocity is decreased by $2 \%$.
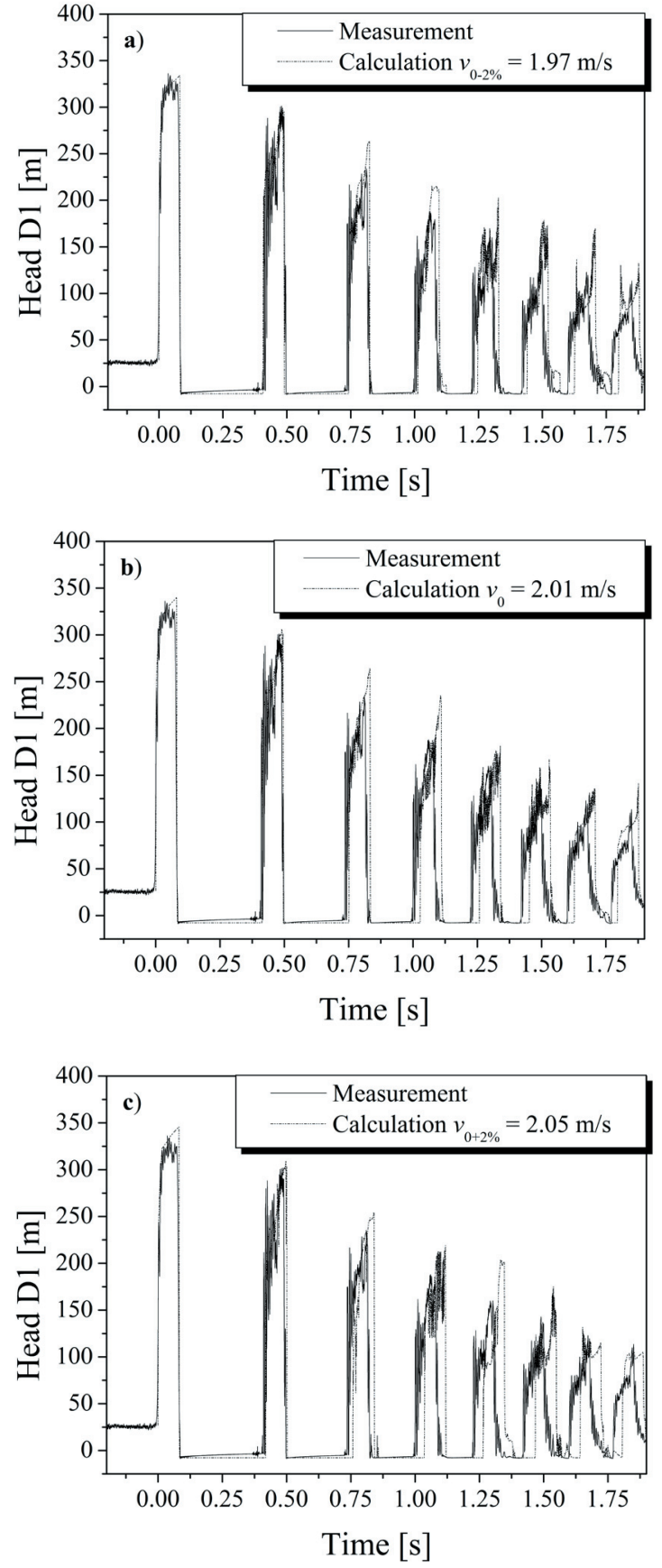

Fig. 4. Comparisons of heads at D1 for Test $B$ : $a_{-5 \%}=1349 \mathrm{~m} / \mathrm{s}$; at a) $v_{0-2 \%}=1.97 \mathrm{~m} / \mathrm{s}$, b) $v_{0}=2.01 \mathrm{~m} / \mathrm{s}$, and c) $v_{0+2 \%}=2.05 \mathrm{~m} / \mathrm{s}$

\subsection{Fast Closing and Opening of the Electro-Pneumatic Valve}

The fast closing and opening of the EV is used to validate the developed numerical model. In this section, two different experimental tests results are presented. The first experimental run represents fast closure of the EV at the initial pressure in the 

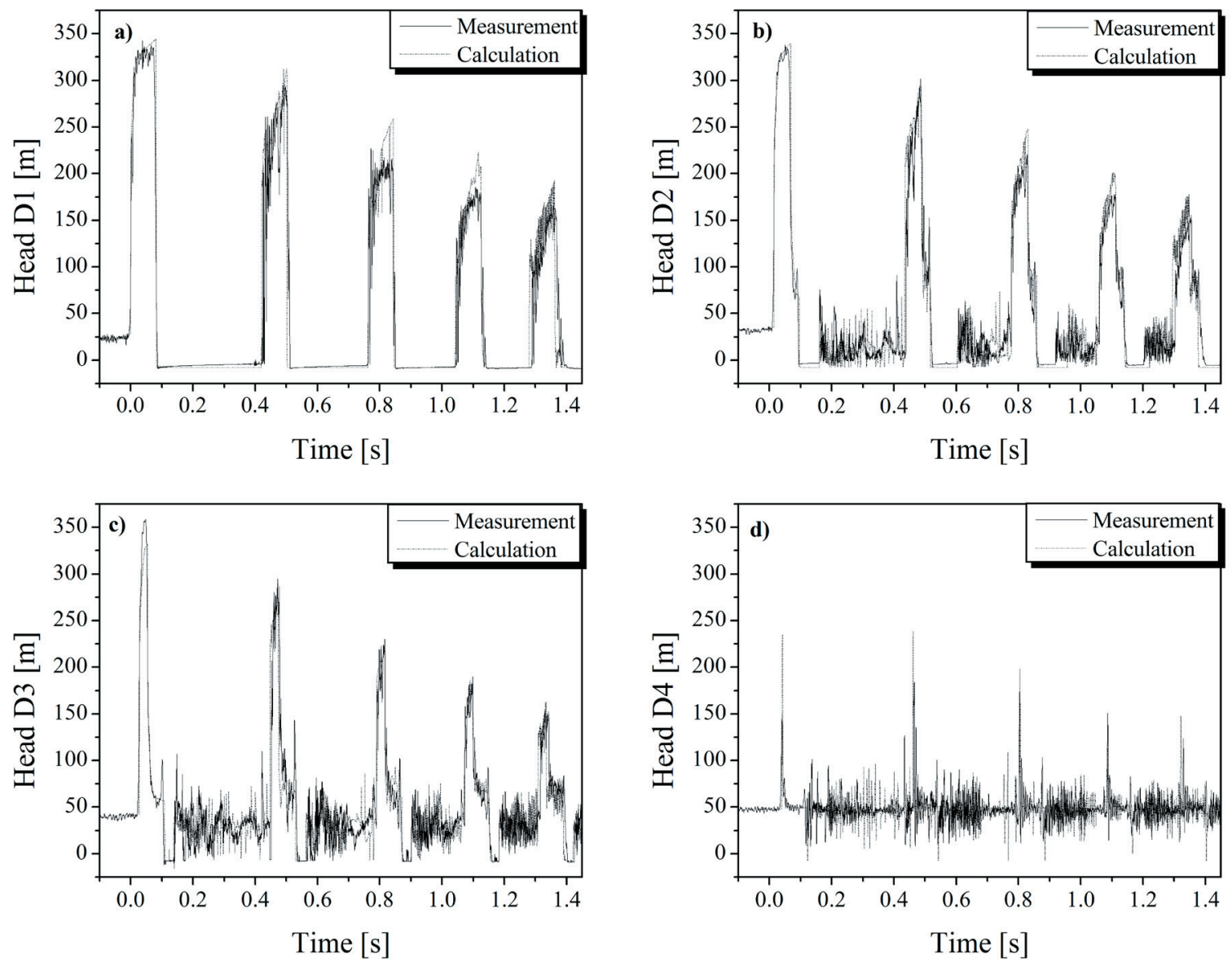

Fig. 5. Comparisons of heads at a) D1, b) D2, c) D3 and d) D4 for Test C: $p_{r}=4$ bar, $v_{0}=2.05 \mathrm{~m} / \mathrm{s}, \Delta t=3.77 \times 10^{-4} \mathrm{~s}, P=2.76$

HPR of $p_{r}=4$ bar and the initial flow velocity in the system of $v_{0}=2.05 \mathrm{~m} / \mathrm{s}$ (Test C). The flow for Test $\mathrm{C}$ is turbulent flow with Reynolds number $\operatorname{Re}=36,900$. The EV measured closing time is $t_{c}=0.018 \mathrm{~s}$. The second run represents the fast opening of the EV with the adjusted pressure in the HPR of $p_{r}=4$ bar and the final pipe velocity of $v_{f}=2.01 \mathrm{~m} / \mathrm{s}$ (Test D).

Fig. 5 presents comparisons of heads at the dynamic pressure transducer positions D1, D2, D3 and $\mathrm{D} 4$ for Test $\mathrm{C}$. The maximum measured heads at all dynamic pressure transducer positions occur during the first pressure pulse except D4 next to the HPR (Fig. 5d). At this position, the maximum head occurs at time $t=0.46 \mathrm{~s}$ as a short duration pressure pulse. The maximum measured values are $H_{\max }=\{341.7 ; 336.4 ; 357.7 ; 181.9\} \mathrm{m}$ for D1, D2, D3 and D4 positions, respectively. The corresponding head rise is $\Delta H=\{314.6 ; 302.6 ; 316.8 ; 134.2\} \mathrm{m}$. The maximum computed heads with the corresponding head rise are as follows: $H_{\max }=\{343.9 ; 338.7 ; 330.9$;
$236.4\} \mathrm{m}$ and $\Delta H=\{319.2 ; 305.5 ; 290.1 ; 188.6\}$ $\mathrm{m}$ for D1, D2, D3 and D4 transducer positions, respectively. The corresponding relative differences between the measured and the computed maximum head values are, $H_{\text {meas }}-H_{\text {comp }}=\{0.6 ; 0.7 ; 8 ; 23\} \%$, respectively. The developed numerical model effectively determines the values of maximum head at positions of D1 and D2 (Figs. 5a and b); this is not the case at positions D3 and D4 (Figs. 5c and d). The maximum measured head occurs at position D3 (Fig. $5 \mathrm{c})$. In the numerical model, the maximum head is at the valve (Fig. 5a). At the valve, there is an alternating growth and collapse of cavitation bubbles, which occur at a constant vapour pressure head (Fig. 5a). Measured and calculated duration of the first large cavity at the EV is $t_{c a v}=\{0.344 ; 0.335\} \mathrm{s}$, respectively. Good agreement between the experimental and the computed results may also be observed along the pipeline at the transducer positions D2, D3 and D4. In cavitation regions along the pipeline, the collapse of a number of vapour bubbles cause small pressure 

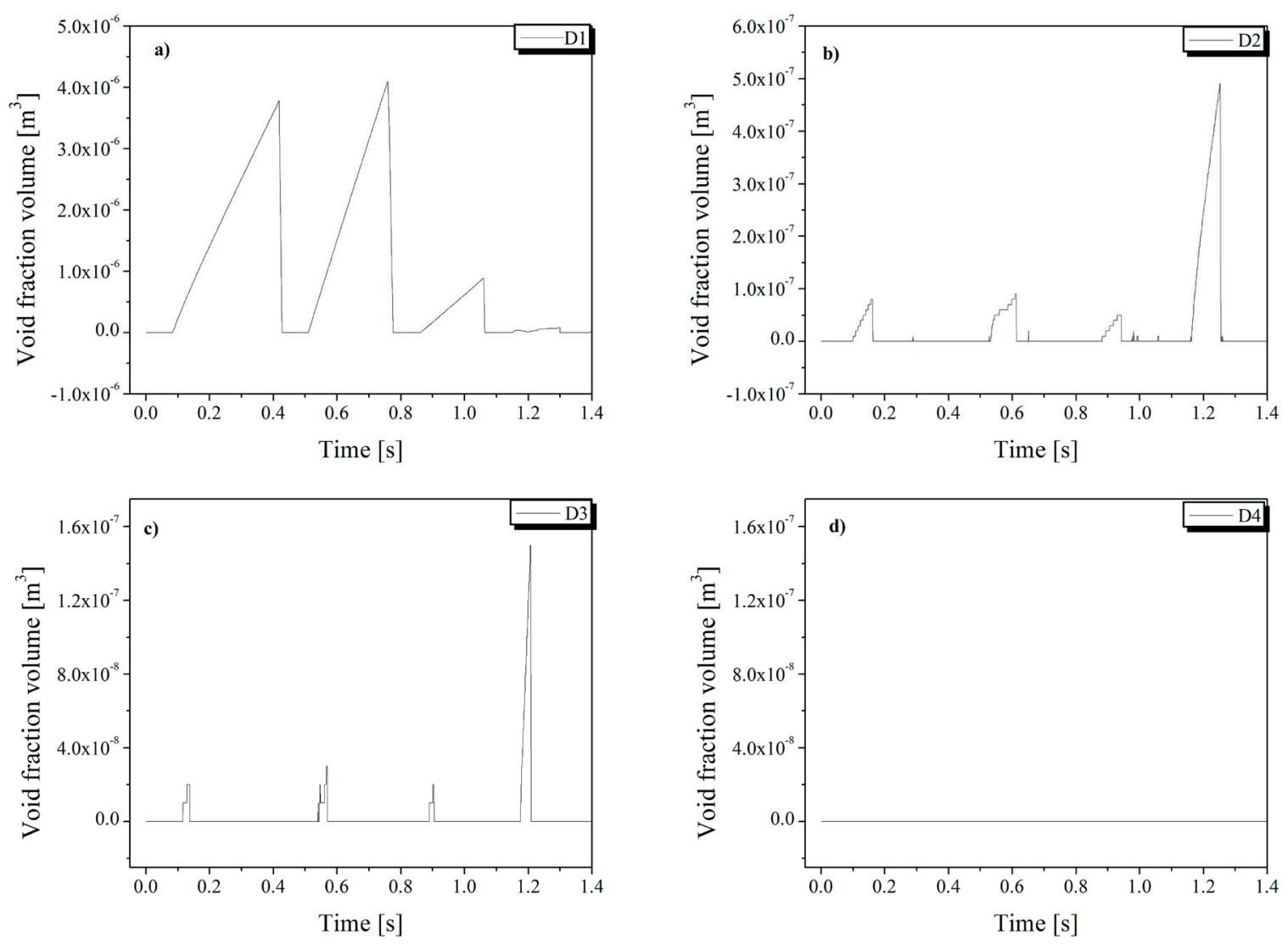

Fig. 6. Calculated void fraction volume at a) D1, b) D2, c) D3 and d) D4 for Test $C$

fluctuations that are registered in the experimental run and simulated in numerical calculations. The calculated results of the void fraction volume for Test $\mathrm{C}$ are shown on Fig. 6. As expected, the maximum void fraction volume occurs at the dynamic pressure transducer position D1.

Fig. 7 shows comparisons of heads at the dynamic pressure transducer positions D1, D2, D3 and D4 for Test D. The EV-measured opening time is $t_{o}=0.011 \mathrm{~s}$. The results of measurements show a characteristic appearance of a high frequency pressure peak at the beginning of the valve opening that is not simulated by the numerical model (Fig. 7a). The peak may be attributed to FSI effects of the EV. Otherwise, the numerical model shows a good match with the results of measurement for the case of the valve opening. After the valve is opened, the head at the D1 drops to the minimum value $\left(H_{\min }=\{3.1\right.$ (measured); 1.5 (computed) $\} \mathrm{m}$ ) and reaches a new steady state without significant oscillations (Fig. 7a). In contrast, head fluctuations at the D2 and D3 positions, after the valve is opened, are much larger (Figs. $7 b$ and c). The maximum measured head of $H_{\max }=53.4 \mathrm{~m}$ occurred at the position D3 at the time $t=0.145 \mathrm{~s}$ and has a higher value than the initial system's head. This is not the case in the numerical model, where the maximum head is lower than the initial one. The minimum measured head of $H_{\min }=-2.7 \mathrm{~m}$ also occurred at position D3 at the time of $t=0.047 \mathrm{~s}$. The head oscillations at position D4 next to the HPR is of minor importance (Fig. 7d). The cavitation does not occur in the considered case of the valve opening.

The maximum measured head rise and drop have been observed at dynamic pressure transducer position D3 for both investigated cases of EV closing and opening. This may be attributed to FSI effects. These effects will be investigated by the authors in the near future.

\subsection{Impact of the Pipeline Length on the Water Hammer Head Rise}

It is commonly known that the water hammer head rise, after rapid valve closure, depends on the initial flow velocity and pressure wave speed according the Joukowsky formulae. In this section, the impact of 

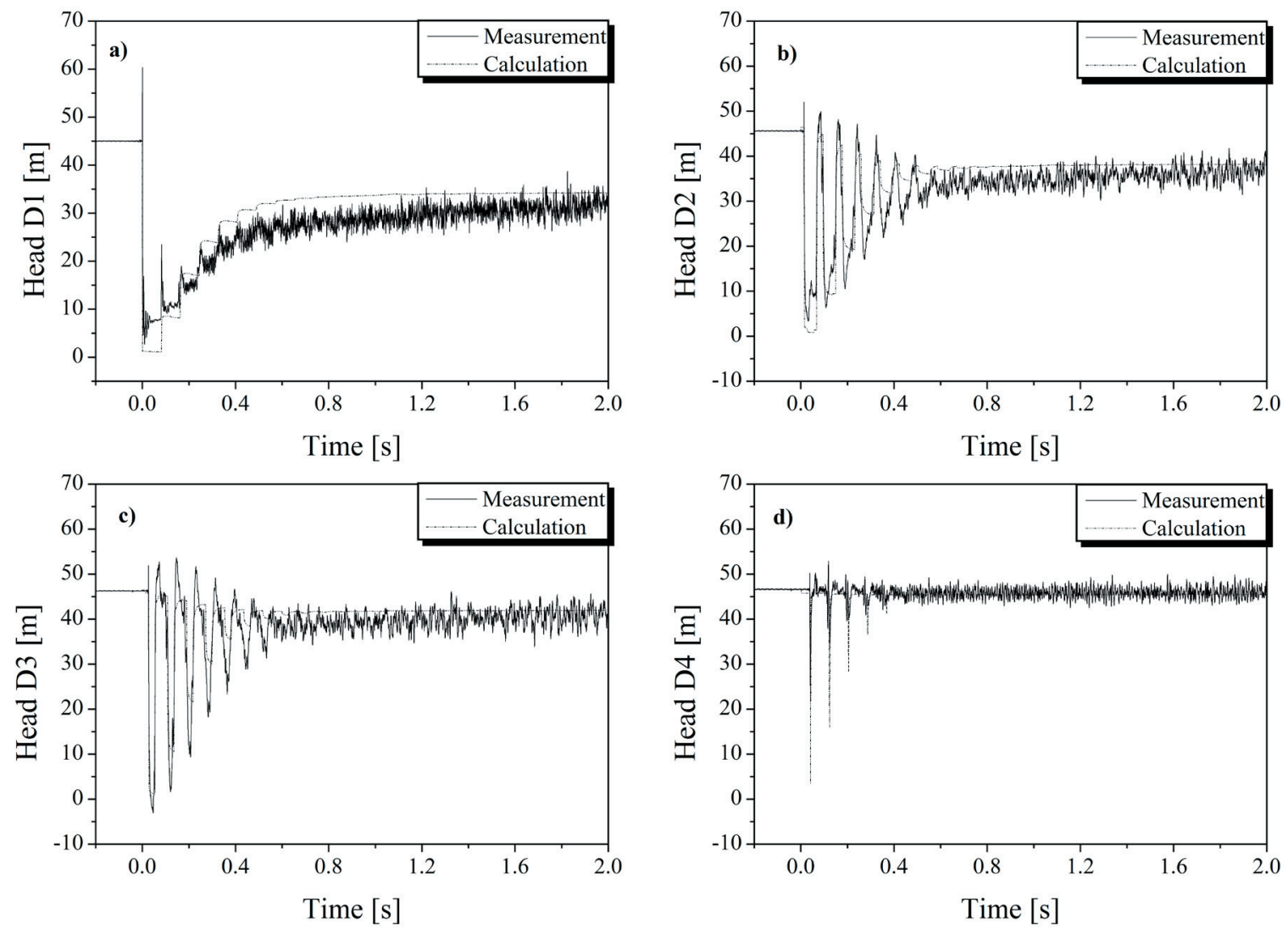

Fig. 7. Comparisons of heads at a) D1, b) D2, c) D3 and d) D4 for Test $D$ : $p_{r}=4$ bar, $v_{f}=2.01 \mathrm{~m} / \mathrm{s}, \Delta t=3.77 \times 10^{-4} \mathrm{~s}, P=2.82$

the pipeline length on the water hammer head rise is investigated. Fast closures of the HVs along the pipeline are performed and with appropriate numerical calculations water hammer in the different system's length is simulated. The hand valves downstream of the dynamic pressure transducers at the positions D1, D2, D3 and D4 have been fast closed in the separate experimental runs and noted as Test E. The initial flow velocity and the pressure in the HPR are the same for all tests investigated, $v_{0}=2.0 \mathrm{~m} / \mathrm{s}$ and $p_{r}=4 \mathrm{bar}$. The corresponding pipe length is $L=\{54.23 ; 35.83$; $18.13 ; 1.74\} \mathrm{m}$, and the hand valve closing time is $t_{c}$ $=\{0.13 ; 0.11 ; 0.1 ; 0.06\} \mathrm{s}$. The HV closing time is nearly the same for D1, D2 and D3 positions. The pressure wave speed in all numerical calculation is adopted as $a=1349 \mathrm{~m} / \mathrm{s}$ and the numerical time step is $\Delta t=\left\{3.77 \times 10^{-4} ; 2.49 \times 10^{-4} ; 1.2 \times 10^{-4} ; 0.15 \times 10^{-4}\right\}$ $\mathrm{s}$, respectively. The water hammer wave reflection time is $2 L / a=\{0.080 ; 0.053 ; 0.027 ; 0.002\} \mathrm{s}$ and it is shorter than the HV closing time in all cases investigated. It means that when the water hammer pressure wave arrives back at the valve, the valve is still open and incomplete water hammer occurs. Fig. 8 shows comparisons of heads at the dynamic pressure transducer positions D1, D2, D3 and D4 for Test E.

The maximum measured head in all cases occurs after the valve is closed, and its values are $H_{\max }=$ $\{287.1 ; 293.2 ; 272.0 ; 71.0\} \mathrm{m}$, respectively. The corresponding measured head rises are $\Delta H=\{261.6$; $260.2 ; 231.8 ; 25.0\} \mathrm{m}$. The computed maximum head and the head rise are $H_{\max }=\{291.2 ; 289.8 ; 269.6$; $71.0\} \mathrm{m}$ and $\Delta H=\{261.4 ; 254.7 ; 228.6 ; 25.0\} \mathrm{m}$. The largest increase in head occurs in the longest pipeline. However, based on the results presented here, a general conclusion cannot be drawn, because the closing time of the valves is not accurately measured but rather is read from the diagram of the pressure changes. To investigate whether the length of the pipeline has an impact on the head rise due to water hammer and how important this impact is, it is necessary that the valve closing time to be much shorter than the pressure wave reflection time. In this way, the full water hammer and head rise could be calculated using the Joukowsky equation and compared with results given by the measurements. In the considered case, using the Joukowsky equation, the calculated head rise is 

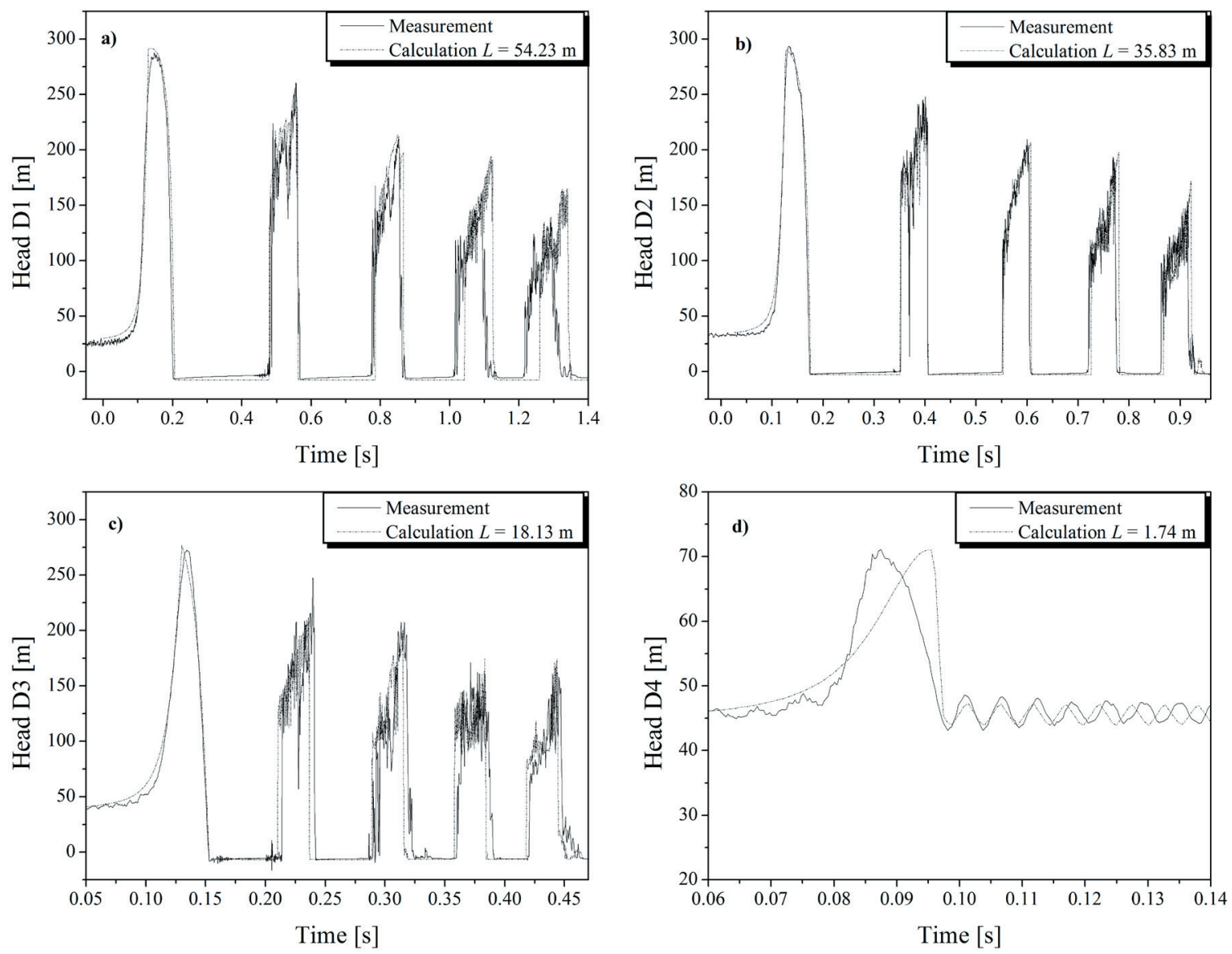

Fig. 8. Comparisons of heads at a) D1, b) D2, c) D3 and d) D4 for Test $E: p_{r}=4$ bar, $v_{0}=2.0 \mathrm{~m} / \mathrm{s}, \quad a=1349 \mathrm{~m} / \mathrm{s}, P=2.83$

$\Delta H=275 \mathrm{~m}$, which is much higher than the measured and calculated values obtained for the valve closing time longer than the pressure wave reflection time. The numerical model shows good agreement with the results of measurements (Figs. 8a, b and c) except to some extent for the case of the hand valve closure at the position D4 (Fig. 8d), where the maximum head is calculated well but the shape differs. The fast closure of the HV close to the HPR causes a head increase and then oscillations that quickly damped out. However, further improvement of the numerical model is necessary in order to successfully simulate water hammer in very short pipelines.

\section{CONCLUSIONS}

In this paper, an experimental apparatus for investigating water hammer and column separation in pipelines has been described in detail. Based on the value of the Ghidaoui et al. parameter $P$, it is concluded that the developed experimental setup is an unsteady friction dominated one. In-house numerical code using a discrete gas cavity model and a convolution-based unsteady friction model has been developed. The numerical results have been compared with the results of measurements for the cases of fast closing and opening both the electro-pneumatic and the hand-operated downstream end valve.

The impact of different numbers of computational reaches was first investigated, and examination of the computed results reveals numerically robust behaviour of the developed numerical model as the number of reaches increases. The influence of variations of pressure wave speed and the uncertainty of electromagnetic flow meter have been investigated, and it is concluded that pressure wave speed should be decreased by $5 \%$, and the initial pipe velocity should be reduced by $2 \%$ compared with initially measured values. The numerical results show very good matches with the results of measurements for the case of fast closing and opening of the EV. The maximum measured head rise and drop have been observed at dynamic pressure transducer position D3 for both investigated cases. In the case of the valve opening, 
the maximum measured head is higher than the initial one, which is not simulated by the numerical model. This may be attributed to FSI effects in the system. Future research may be seen in investigations of FSI impact of the EV as well as possible influence of the pipeline bends on the occurrence of the maximum head in the system. Due to the very good agreement between the computed and measured results and the robust numerical algorithm, the discrete gas cavity model using the convolution based unsteady friction term is recommended for engineering practice.

\section{ACKNOWLEDGMENTS}

The authors gratefully acknowledge the support of the Ministry of Science of Montenegro (MSM) and the Slovenian Research Agency (ARRS) conducted through the projects "Analysis of transient phenomena in hydraulic and aeromechanical systems" (MSM), "Investigation of water hammer effects in a test facility" (MSM, ARRS) and "Unsteady skin friction modelling in hydraulic piping systems" (ARRS).

\section{NOMENCLATURE}

\begin{tabular}{|c|c|}
\hline$A$ & pipe area $\left[\mathrm{m}^{2}\right]$, \\
\hline$a$ & water hammer wave speed $[\mathrm{m} / \mathrm{s}]$, \\
\hline$D$ & pipe diameter $[\mathrm{m}]$, \\
\hline E & Young's modulus of elasticity [Pa], \\
\hline$f$ & friction factor $[-]$ \\
\hline$g$ & gravitational acceleration $\left[\mathrm{m} / \mathrm{s}^{2}\right]$, \\
\hline$H$ & piezometric head (head) [m], \\
\hline$K$ & water bulk modulus of elasticity [Pa], \\
\hline$L$ & pipe length, length $[\mathrm{m}]$ \\
\hline$m_{k}, n_{k}$ & exponential sum coefficients [-], \\
\hline$N$ & number of computational reaches [-], \\
\hline$P$ & Ghidaoui et al. parameter [-], \\
\hline$p$ & pressure $[\mathrm{Pa}]$ \\
\hline$Q$ & discharge $\left[\mathrm{m}^{3} / \mathrm{s}\right]$ \\
\hline$Q_{\text {in }}$ & node upstream end discharge $\left[\mathrm{m}^{3} / \mathrm{s}\right]$, \\
\hline$Q_{\text {out }}$ & node downstream end discharge $\left[\mathrm{m}^{3} / \mathrm{s}\right]$, \\
\hline $\mathrm{Re}$ & Reynolds number [-], \\
\hline$t, t^{*}$ & time $[\mathrm{s}]$ \\
\hline$t_{c}$ & valve closing time $[\mathrm{s}]$ \\
\hline$t_{o}$ & valve opening time $[\mathrm{s}]$ \\
\hline$V$ & volume $\left[\mathrm{m}^{3}\right]$ \\
\hline$v$ & velocity $[\mathrm{m} / \mathrm{s}]$ \\
\hline$W$ & weighting function [-], \\
\hline$x$ & distance $[\mathrm{m}]$ \\
\hline$y_{k}$ & component of the weighting function [-], \\
\hline$\alpha$ & gas void fraction $[-]$, \\
\hline$\Delta t$ & time step $[\mathrm{s}]$ \\
\hline$\Delta x$ & reach length $[\mathrm{m}]$, \\
\hline
\end{tabular}

$v \quad$ kinematic viscosity $\left[\mathrm{m}^{2} / \mathrm{s}\right]$,

$\tau \quad$ dimensionless time [-],

$\psi \quad$ weighting factor [-].

Subscripts:

$f \quad$ final

$g \quad$ gas

$\max$ maximum

$q \quad$ quasi-steady

$u \quad$ unsteady

$0 \quad$ steady state conditions

Superscripts:

* absolute pressure

\section{REFERENCES}

[1] Wylie, E.B., Streeter, V.L. (1993). Fluid Transients in Systems. Prentice-Hall, Englewood Cliffs.

[2] Chaudhry, M.H. (2014). Applied Hydraulic Transients. $3^{r d}$ ed., Springer, New York, DOI:10.1007/978-1-46148538-4.

[3] Bergant, A., Tijsseling, A.S., Vítkovský, J.P., Covas, D.I.C., Simpson, A.R., Lambert, M.F. (2008). Parameters affecting water hammer wave attenuation, shape and timing. Part 1: Mathematical tools. IAHR Journal of Hydraulic Research, vol. 46, no. 3, p. 373381, DOI:10.3826/jhr.2008.2848.

[4] Bergant, A., Tijsseling, A.S., Vítkovský, J.P., Covas, D.I.C., Simpson, A.R., Lambert, M.F. (2008). Parameters affecting water hammer wave attenuation, shape and timing. Part 2: Case studies. IAHR Journal of Hydraulic Research, vol. 46, no. 3, p. 382-391, DOI:10.3826/jhr.2008.2847.

[5] Bergant, A., Simpson, A.R., Tijsseling, A.S. (2006). Waterhammer with column separation: A historical review. Journal of Fluids and Structures, vol. 22, no. 2, p. 135-171, DOI:10.1016/j.jfluidstructs.2005.08.008.

[6] Adamkowski, A., Lewandowski, M. (2012). Investigation of hydraulic transients in a pipeline with column separation. ASCE Journal of Hydraulic Engineering, vol. 138, no. 11, p. 935-944, DOI:10.1061/ (ASCE)HY.1943-7900.0000596.

[7] Bergant, A., Kruisbrink, A., Arregui, F. (2012). Dynamic behavior of air valves in a large-scale pipeline apparatus. Strojniški vestnik - Journal of Mechanical Engineering, vol. 58, no. 4, p. 225-237, DOI:10.5545/ sv-jme.2011.032.

[8] Bergant, A., Simpson, A.R. (1999). Pipeline column separation flow regimes. ASCE Journal of Hydraulic Engineering, vol. 125, no. 8, p. 835-848, DOI:10.1061/ (ASCE)0733-9429(1999)125:8(835).

[9] Vardy, A.E. (1980). Unsteady flow: fact and friction. Proceedings of the $3^{\text {rd }}$ International Conference on Pressure Surges, BHRA, Cantenbury, p. 15-26.

[10] Brunone, B., Karney, B.W., Mecarelli, M., Ferrante, M. (2000). Velocity profiles and unsteady pipe friction in transient flow. Journal of Water Resources 
Planning and Management, vol. 126, no. 4, p. 236-244, DOI:10.1061/(ASCE)0733-9496(2000)126:4(236).

[11] Pezzinga, G., Brunone, B. (2006). Turbulence, friction, and energy dissipation in transient pipe flow. Brocchini, M., Trivellato, F. (eds.), Vorticity and Turbulence Effects in Fluid Structure Interaction, WIT Press, Southampton, p. 213-236.

[12] He, S., Ariyaratne, C., Vardy, A.E. (2008). A computational study of wall friction and turbulence dynamics in accelerating pipe flows. Computers \& Fluids, vol. 37, no. 6, p. 674-689, DOI:10.1016/j. compfluid.2007.09.001.

[13] Bergant, A., Simpson, A.R., Vítkovský, J. (2001). Developments in unsteady pipe flow friction modelling. IAHR Journal of Hydraulic Research, vol. 39, no. 3, p. 249-257, DOI:10.1080/00221680109499828.

[14] Riasi, A., Raisee, M., Nourbekhsh, A. (2010). Simulation of transient flow in hydroelectric power plants using unsteady friction. Strojniški vestnik Journal of Mechanical Engineering, vol. 56, no. 6, p. 377-384.

[15] Tijsseling, A.S. (1996). Fluid-structure interaction in liquid-filled pipe systems: a review. Journal of Fluids and Structures, vol. 10, no. 2, p. 109-146, DOI:10.1006/ jfls.1996.0009.

[16] Wiggert, D.C., Tijsseling, A.S. (2001). Fluid transients and fluid-structure interaction in flexible liquid-filled piping. ASME Applied Mechanics Reviews, vol. 54, no. 5, p. 455-481, DOI:10.1115/1.1404122.

[17] Ahmadi, A., Keramat, A. (2010). Investigation of fluid-structure interaction with various types of junction coupling. Journal of Fluids and Structures, vol. 26, no. 7-8, p. 1123-1141, DOI:10.1016/j. jfluidstructs.2010.08.002.

[18] Covas, D.I.C., Stoianov, I., Mano, J.F., Ramos, H., Graham, N., Maksimović, Č. (2004). The dynamic effect of pipe-wall viscoelasticity in hydraulic transients. Part I - experimental analysis and creep characterisation. IAHR Journal of Hydraulic Research, vol. 42, no. 5, p. 517-532, DOI:10.1080/00221686.200 4.9641221.

[19] Covas, D.I.C., Stoianov, I., Mano, J.F., Ramos, H., Graham, N., Maksimović, Č. (2005). The dynamic effect of pipe-wall viscoelasticity in hydraulic transients. Part II - model development, calibration and verification. IAHR Journal of Hydraulic Research, vol. 43, no. 1, p. 56-70, DOI:10.1080/00221680509500111.

[20] Soares, A.K., Covas, D.I.C., Reis, L.F.R. (2008). Analysis of PVC pipe wall viscoelasticity during water hammer. ASCE Journal of Hydraulic Engineering, vol. 134, no. 9, p. 1389-1394, DOI:10.1061/(ASCE)07339429(2008)134:9(1389).

[21] Meniconi, S., Brunone, B., Ferrante, M., Massari, C. (2013). Numerical and experimental investigation of leaks in viscoelastic pressurized pipe flow. Drinking Water Engineering and Science, vol. 6, p. 11-16, DOI:10.5194/dwesd-5-473-2012.
[22] Vítkovský, J.P., Stephens, M., Bergant, A., Lambert, M.F., Simpson, A.R. (2004). Efficient and accurate calculation of Zielke and Vardy-Brown unsteady friction in pipe transients. Proceedings of the 9th International Conference on Pressure Surges, BHR Group, Chester, p. 405-419.

[23] Wylie, E.B. (1984). Simulation of vaporous and gaseous cavitation. ASME Journal of Fluids Engineering, vol. 106, no. 3, p. 307-311, DOI:10.1115/1.3243120.

[24] Ghidaoui, M.S, Mansour, S.G.S., Zhao, M. (2002). Applicability of quasisteady and axisymmetric turbulence models in water hammer. ASCE Journal of Hydraulic Engineering, vol. 128, no. 10, p. 917-924, DOI:10.1061/(ASCE)0733-9429(2002)128:10(917).

[25] Thorley, A.R.D (1971). Influence of variations of transient velocity on resonating frequencies. ASME Winter Annual Meeting, Washington D.C., p. 1-9.

[26] Bergant, A., Karadžić, U., Vítkovský, J.P., Vušanović, I., Simpson, A.R. (2005). A discrete-gas cavity model that considers the frictional effects of unsteady pipe flow. Strojniški vestnik - Journal of Mechanical Engineering, vol. 51, no. 11, p. 692-710.

[27] Duan, H-F., Ghidaoui, M., Lee, P.J., Tung, Y-K. (2010). Unsteady friction and visco-elasticity in pipe fluid transients. IAHR Journal of Hydraulic Research, vol. 48, no. 3, p. 354-362, DOI:10.1080/00221681003726247.

[28] Theissen, H. (1986). Simulation von hydraulischen Systemen mit langen Rohrleitungen. Ö+P. Ölhydraulik und Pneumatik, vol. 30, no. 3, p. 209-216.

[29] Navrátil, P., Balátê, J. (2011). Simulation of control of multi-variable control loop: steam turbine. International Journal of Simulation Modelling, vol. 10, no. 2, p. 53-65, DOI:10.2507/IJSIMM10(2)1.167.

[30] Zielke, W. (1968). Frequency-dependent friction in transient pipe flow. ASME Journal of Basic Engineering, vol. 90, no. 1, p. 109-115, DOI:10.1115/1.3605049.

[31] Vítkovský, J.P., Bergant, A., Simpson, A.R., Lambert, M.F. (2006). Systematic evaluation of one-dimensional unsteady friction models in simple pipelines. ASCE Journal of Hydraulic Engineering, vol. 132, no. 7, p. 696-708, DOI:10.1061/(ASCE)07339429(2006)132:7(696).

[32] Vardy, A.E., Brown, J.M.B. (2003). Transient turbulent friction in smooth pipe flows. Journal of Sound and Vibration, vol. 259, no. 5, p. 1011-1036, DOI:10.1006/ jsvi.2002.5160.

[33] Vardy, A.E., Brown, J.M.B. (2004). Transient turbulent friction in fully rough pipe flows. Journal of Sound and Vibration, vol. 270, no. 1-2, p. 233-257, DOI:10.1016/ S0022-460X(03)00492-9.

[34] Karadžić, U., Bergant, A. (2012). Pipeline apparatus for investigation of water hammer and column separation phenomena at the University of Montenegro. Proceedings of the $2^{\text {nd }}$ IAHR Europe Congress, Munich, Paper B26.

[35] Coleman, H.W., Steele, W.G. (1989). Experimentation and Uncertainty Analysis for Engineers. John Wiley and Sons, New York. 